\title{
Treatment of Rheumatoid Arthritis with Marine and Botanical Oils: Influence on Serum Lipids
}

\author{
Barbara C. Olendzki, ${ }^{1}$ Katherine Leung, ${ }^{2}$ Susan Van Buskirk, ${ }^{3}$ \\ George Reed, ${ }^{2}$ and Robert B. Zurier ${ }^{4}$ \\ ${ }^{1}$ Center for Integrative Nutrition, Division of Preventive and Behavioral Medicine, University of Massachusetts Medical School, \\ Worcester, MA 01655, USA \\ ${ }^{2}$ Division of Preventive and Behavioral Medicine, University of Massachusetts Medical School, Worcester, MA 01655, USA \\ ${ }^{3}$ Department of Family Medicine and Community Health, University of Massachusetts Medical School, Worcester, MA 01655, USA \\ ${ }^{4}$ Division of Rheumatology, University of Massachusetts Medical School, Worcester, MA 01655, USA
}

Correspondence should be addressed to Barbara C. Olendzki, barbara.olendzki@umassmed.edu

Received 31 December 2010; Revised 6 June 2011; Accepted 25 July 2011

Copyright (C) 2011 Barbara C. Olendzki et al. This is an open access article distributed under the Creative Commons Attribution License, which permits unrestricted use, distribution, and reproduction in any medium, provided the original work is properly cited.

\begin{abstract}
The gap in mortality between patients with rheumatoid arthritis (RA) and the general population (1.5-3.0 fold risk) is increasing. This disparity is attributable mainly to cardiovascular disease (CVD), as the CVD risk is comparable to patients with diabetes mellitus. The purpose of this study is to determine whether borage seed oil rich in gamma-linolenic acid, fish oil rich in eicosapentaenoic acid (EPA) and docosahexaenoic acid (DHA), or the combination of both oils are useful treatments for dyslipidemia in patients with RA. We randomized patients into a double blind, 18 month trial. Mixed effects models were used to compare trends over time in serum lipids. No significant differences were observed between the three groups: All three treatment groups exhibited similar meaningful improvement in the lipid profile at 9 and 18 months. When all groups were combined, these treatments significantly reduced total and LDL-cholesterol and triglycerides, increased HDL-cholesterol, and improved the atherogenic index. All improvements observed at 9 months persisted at 18 months $(P<0.001$ verses baseline $)$. Conclusion. Marine and botanical oils may be useful treatment for rheumatoid arthritis patients who are at increased risk for cardiovascular disease compared to the general population.
\end{abstract}

\section{Introduction}

Over the past 30 years, substantial progress has been made in the medical and surgical management of patients with rheumatoid arthritis (RA). Despite this progress, there is an increasing gap in mortality between patients with RA (1.53.0 fold risk) and the general population. The disparity is mainly attributable to cardiovascular disease (CVD) [1] as the CVD risk is comparable to patients with diabetes mellitus $[2,3]$. Although the reasons for this gap are not entirely clear, the traditional risk of abnormalities in lipid profiles [4] appears to be enhanced by a chronic increase in inflammatory cytokines [5], resulting in accelerated atherosclerosis. In fact, the elevated risk of cardiovascular disease for patients with RA indicates that atherosclerosis may in fact begin at lower thresholds of lipid dysfunction and inflammation than those in the general population, making the lipid profile and other risk factors of particular concern for patients with RA
[6]. In a prospective study, [7] atherogenic lipid profiles were considerably worse in people who later met criteria for RA (as much as 10 years later) than those in matched controls. Although recent advances in the treatment of RA, especially with agents designed to block the actions of tumor necrosis factor alpha (TNF $\alpha$ ), have improved the course of the disease [8] and endothelial function [9], results of studies of their influence on circulating lipids are mixed, and adequate evidence for or against such benefit is not available [10-12]. Due to the lack of supporting data, patients with RA, many of whom are limited in their ability to exercise to improve the lipid profile and the risk of CVD [13], have an urgent need for other treatments to control their dyslipidemia.

It is clear that an increased intake of polyunsaturated fatty acids can improve their lipid profile [14]. Abundant experimental evidence supports the view that prostaglandins, thromboxanes, and leukotrienes (collectively termed eicosanoids), derived from polyunsaturated fatty acids, and 


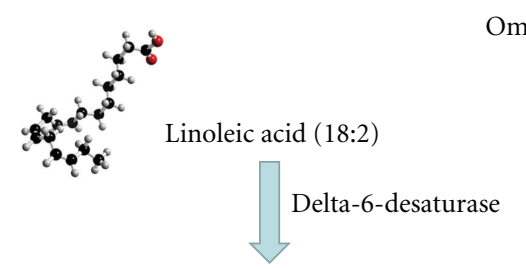

Gamma-linolenic acid (18:3)

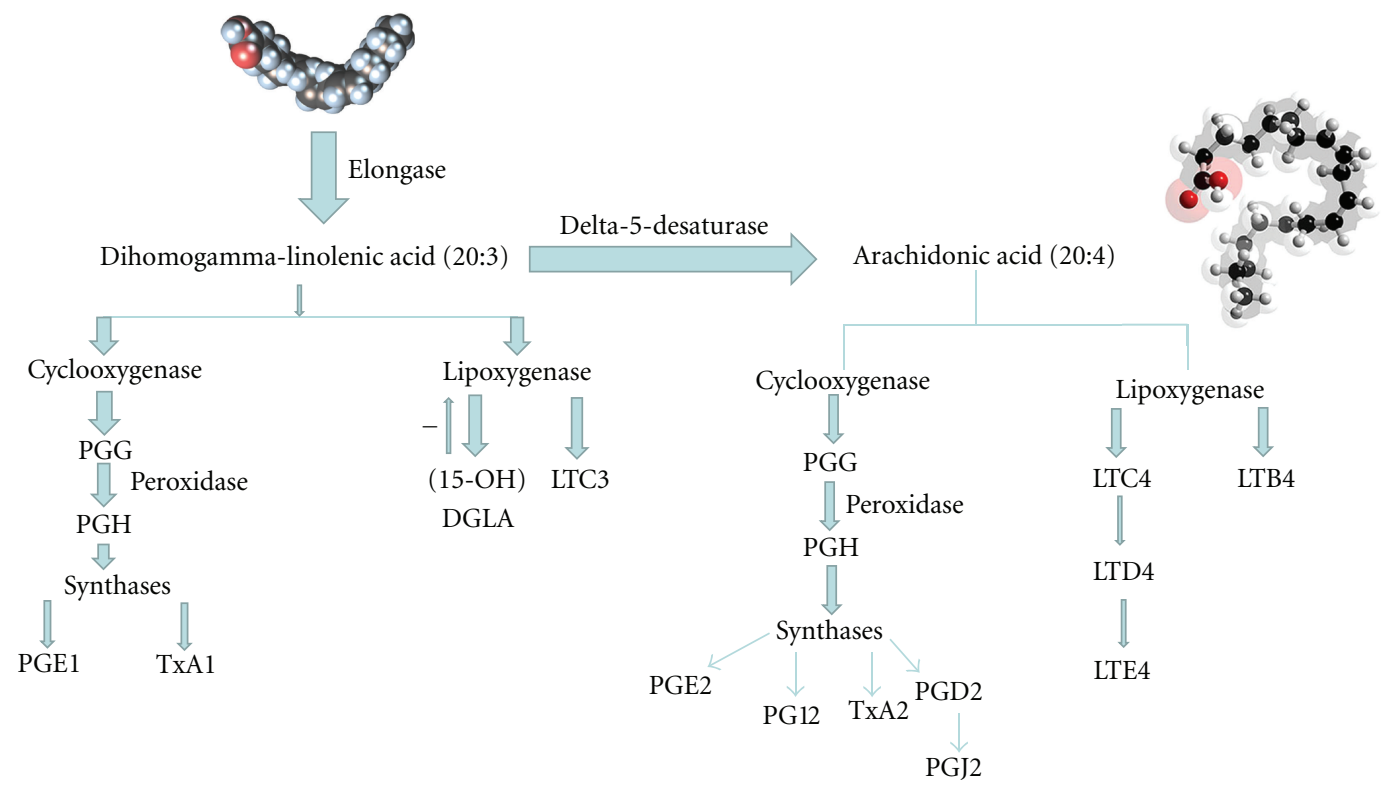

FIGURE 1

participate in development and regulation of immunological and inflammatory responses [15-18]. The fatty acids themselves, by virtue of their incorporation into cell membranes and signal transduction elements, also have effects on cells involved in inflammation and immune responses that are independent of eicosanoids [18, 19]. A disease such as RA, characterized by abnormal immune responses, persistent inflammation, and joint tissue injury [20], may, therefore, be amenable to control by treatment with oils rich in specific polyunsaturated fatty acids.

Gamma-linolenic acid (GLA: 18:3 omega 6, see Figure 1) is an essential fatty acid found in certain plant seed oils, including borage seed oil. GLA is metabolized to dihomogamma-linolenic acid (DGLA; 20:3 omega 6), the immediate precursor of prostaglandin $\mathrm{E}_{1}\left(\mathrm{PGE}_{1}\right)$, an eicosanoid with anti-inflammatory and immunoregulatory properties [18]. In addition, GLA cannot be converted to inflammatory leucotrienes by 5-lipoxygenase. Instead, it is converted to 15-hydroxy-DGLA which has the additional virtue of suppressing 5-lipoxygenase activity [21]. GLA and DGLA also modulate immune responses in an eicosanoid-independent manner by acting directly on T lymphocytes [18] and GLA suppresses acute and chronic inflammation, including arthritis, in animal models [18]. In addition, fish oil, rich in eicosapentaenoic acid (EPA; 20:5 omega 3, see Figure 2) and docosahexanoic acid (DHA; 22:6 w-3), suppresses formation of the inflammatory eicosanoids $\mathrm{PGE}_{2}$, thromboxane $\mathrm{A}_{2}$
$\left(\mathrm{TXA}_{2}\right)$, and leucotriene $\mathrm{B}_{4}\left(\mathrm{LTB}_{4}\right)$. Randomized, placebo controlled double blind trials indicated that fish oil treatment of patients with RA result in clinical improvement, and those that monitored NSAID use suggest that fish oil treatment has an NSAID sparing effect [22].

A combination of EPA- and GLA-enriched oils exhibits synergy in reduction of synovitis in animal models [23], and administration of black currant seed oil, which contains the n-3 fatty acid alpha-linolenic acid (which is converted to EPA) and the n-6 GLA, suppresses active synovitis in patients with RA [24]. Taken together, these studies suggest that both EPA and GLA are beneficial therapies for patients with RA. With this knowledge, we carried out an 18-month, multicenter, randomized, double-blind, phase 3 trial of borage seed oil, fish oil, and a combination of both oils in patients with RA and active synovitis, to determine whether the combination of oils is superior to either oil used alone for the treatment of RA. Clinical outcomes of that study will be presented elsewhere. The object of the study presented here is to assess the influence of marine and botanical oils on serum lipids in patients with RA.

\section{Methods and Materials}

The study was an 18-month randomized double-blind comparison of borage oil, fish oil, or a combination of both oils in RA patients with active joint inflammation. 


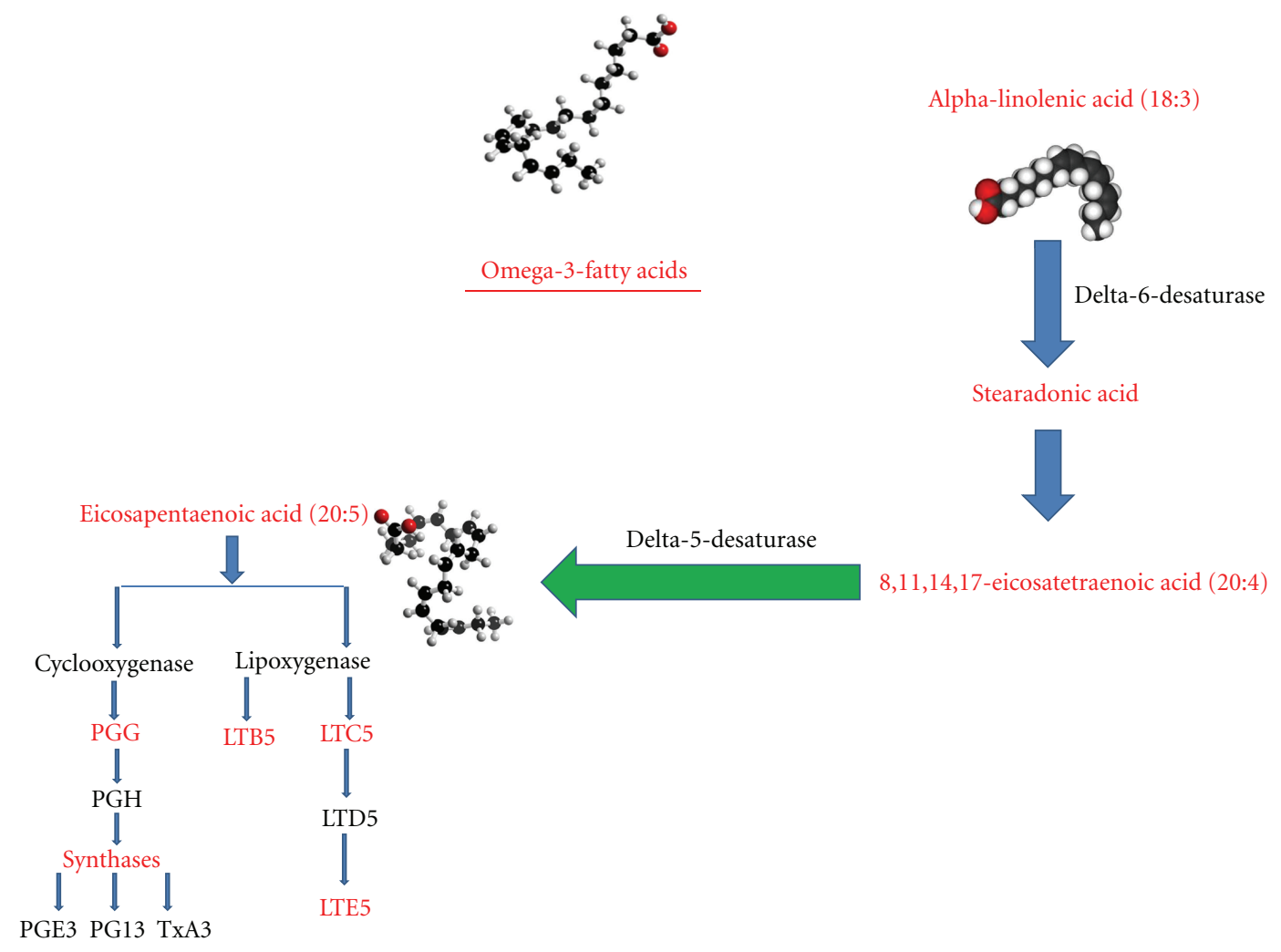

FIgURe 2

Patients received 3.5 gm omega- 3 fatty acids daily in a $2.1 \mathrm{gm} \mathrm{EPA} / 1.4 \mathrm{gm} \mathrm{DHA}$ ratio (7 fish oil and 6 sunflower oil capsules daily), $1.8 \mathrm{gm} / \mathrm{d}$ GLA ( 6 borage oil and 7 sunflower oil capsules/d), or 7 fish oil and 6 borage oil capsules daily (combination therapy). All capsules were identical in appearance and color and were purchased from the manufacturer, Bioriginal Food and Service Corp, Saskatoon, Canada, who shipped the capsules in opaque plastic bottles to the University of Massachusetts University Hospital pharmacy, from whence they were distributed to participating centers. Capsules were taken in 2 or 3 divided doses with meals.

The protocol was reviewed and approved initially by the Committee for the Protection of Human Subjects at the University of Massachusetts Medical School and the Food and Drug Administration. Subsequent approvals were obtained from the Review Boards at the University of Alabama, Geisenger Clinic, Fallon Health Care, and the New England IRB. Written informed consent was obtained from each patient.

Patients were eligible to participate in the study if they had RA according to the 1987 criteria of the American Rheumatism Association [25], were in functional class I, II or III according to the revised criteria of the American College of Rheumatology [26], and were between the ages of 18 and 85. Patients were on a stable dose of drugs for RA for at least 2 months before the screening visit and a total duration of therapy of at least 6 months. Doses of nonsteroidal anti-inflammatory drugs (NSAID) and/or prednisone $(<10 \mathrm{mg} / \mathrm{d})$ were stable for at least 1 month before screening.
Patients were ineligible for the study if they had been treated with any investigational drug within 1 month of entry. If a patient was taking a fish oil supplement, the dose was stable and $\leq 2000 \mathrm{mg} / \mathrm{d}$ for 2 months before screening. If a patient was taking a borage oil supplement, the dose was stable and $\leq 2000 \mathrm{mg} / \mathrm{d}$ for 2 months before screening. An AST, ALT, or creatinine $>1.5$ times the upper limit of normal or a total bilirubin $>1.8 \mathrm{mg} / \mathrm{dL}$ excluded patients from the trial. Patients were instructed to maintain their typical diet.

The lipid profile was assessed at baseline, 9, and 18 months. Diet was assessed by 24-hour dietary assessment calls (24-HR), performed at baseline and 18 months. Both laboratory evaluation and 24-HR were obtained in most patients who dropped out of the study before 18 months and after 3 months. These results are included in the analysis, and were assigned to the closest 9-month interval to the date of patient's termination in the study.

2.1. Dietary Assessment. To measure the effects of supplemental polyunsaturated fats upon lipids, it is necessary to measure the impact, if any, of the background diet. Because a single 24-HR cannot assess day-to-day variation in dietary intake [27], 3 unannounced 24-HRs were conducted on randomly selected days within a 3 -week period (two weekdays and one weekend) at baseline and 18 months or time of the final visit. The dietary assessments, including reported intake of supplemental non-study marine and botanical oils or phytosterols, were completed utilizing a computer-assisted telephone interview with a multiple pass 
technique [28]. The 24-HR dietary recalls were administered by non-intervention registered dietitians, blinded to the patients' treatment group, and trained to collect dietary data using our interview system. The 24-HR-derived data were analyzed using the University of Minnesota Nutrition Coordinating Center Nutrition Data System for Research software (annually updated, current version: NDS-R 2009). Limitations to 24 -HR dietary assessment in this population include factors related to self report, including possible underreporting of nutrient intake which has been observed in several studies [29].

2.2. Laboratory Measurement Methodology. Total cholesterol (TC) and triglyceride (TG) values were measured by conventional enzymatic methods. Briefly, cholesterol esters are converted to a colored quinine imine product. For HDL cholesterol, the lipoprotein particles are solubilized and release HDL cholesterol to react with cholesterol esterase and oxidase in the presence of chromogens to produce a color product. LDL cholesterol is calculated [30] according to the Friedewald Calculation which is TC-HDL $-(\mathrm{TG} \div 5)=\mathrm{LDL}$. Atherogenic index of plasma (AIP) was used to measure the risk of hypertension, diabetes, and vascular events in this population. The calculation of AIP is $\log 10$ triglyceride/ high-density lipoprotein cholesterol [31].

2.3. Statistical Methods. The three treatment arms were characterized at baseline using frequencies for categorical variables and means and standard deviations for continuous variables. Differences in mean values at 18 months or at the final visit were assessed for change in diet by the Student $t$ test [23]. Outcomes that were not normally distributed were $\log$ transformed for calculation of $P$ values. Nontransformed data are reported for changes from baseline. To assess the effect of the intervention on lipids, lipid values were modeled using linear mixed modeling as a function of time (baseline, 9 month and 18 month, or the final visit treated as a categorical variable to allow for nonlinear trajectories), treatment arm, and their interaction, with adjustment for baseline value. To assess the overall changes over time, outcome measures were modeled using linear mixed modeling as a function of time, treatment arm, and with adjustment for baseline value. All analyses were intention to treat. Analyses included all participants with a baseline lipid measure.

\section{Results}

One hundred fifty-six patients were randomized, 56 received fish oil, 53 received borage seed oil, and 47 received both fish and borage seed oils. Patients were stratified by site (thus randomized to group within each site), and all sites were combined, resulting in non-significant differences per group. Serum lipids were obtained in 146 patients $(93.6 \%)$ at baseline, 84 patients $(53.8 \%)$ at 9 months, and 69 patients (44.2\%) at 18 months.

Another 34 patients were screened but not randomized for the following reasons: arthritis medicine dose was not stable, too few tender joints, anticoagulated, high fish oil intake, high borage seed oil intake, medical issues, or
TABLE 1: Baseline characteristics in patients with rheumatoid arthritis.

\begin{tabular}{lcc}
\hline & \multicolumn{2}{c}{ Total $(N=146)^{*}$} \\
\hline Age & Mean & SD \\
BMI $\left(\mathrm{kg} / \mathrm{m}^{2}\right)$ & 59.24 & 11.58 \\
\hline & 30.55 & 8.3 \\
\hline Gender & $\mathrm{N}$ & \\
$\quad$ Male & 28 & $19.2 \%$ \\
$\quad$ Female & 118 & $80.8 \%$ \\
\hline Marital status & & \\
$\quad$ Married & 100 & $69.0 \%$ \\
$\quad$ Other & 45 & $31.0 \%$ \\
\hline Race-collapsed & & \\
$\quad$ White & 132 & $90.4 \%$ \\
$\quad$ Minority & 14 & $9.6 \%$ \\
\hline Work status & & \\
$\quad$ Full time & 51 & $9.60 \%$ \\
Part time & 14 & $55.50 \%$ \\
$\quad$ Other & 81 &
\end{tabular}

${ }^{*}$ None of the demographics are significantly different across the groups at baseline.

abnormal laboratory values. The overall drop-out rate was 51\% and was similar across groups: 25 in the borage oil group, 28 in the fish oil group, and 22 in the combination group. Reasons for dropout were mainly gastrointestinal distress (belching, bloating, diarrhea, nausea, cramping) or an inability to swallow the large number of rather sizable capsules.

Patient characteristics at baseline are presented in Table 1 . The mean age of participants was 59 years and the sample predominantly female $(80 \%)$. Most were white $(90 \%)$, married $(69 \%)$, and had a mean body mass index (BMI) of 30.5. An equal number were retired (33\%) or working full time (34\%), and 16\% listed themselves as disabled. There were no significant differences between groups.

3.1. Diet. No significant change in dietary intake of fatty acids was seen (Table 2$)$. However, a significant $(P<0.001)$ reduction in sources of dietary calcium $(\sim 200 \mathrm{mg})$ and a slight increase ( $1 \%$ of total calories) in protein intake were observed.

3.2. Weight. No significant differences in weight between groups were observed. Analysis was done using log-transformed weight; however, results are from the original scale. The mean increase when all groups were combined across the entire study was not significant: $0.5 \mathrm{lb}$ increase at 9 months and $0.4 \mathrm{lb}$ increase at 18 months (Table 4 ).

3.3. Lipids. There were no significant differences between groups for any lipid measure, with the exception of triglycerides. Therefore, all groups were, combined to evaluate the influence of marine and botanical oils on serum lipids 
TABLE 2: Change in dietary factors from baseline to 18 months.

\begin{tabular}{lcc}
\hline Change in & Mean & $95 \%$ CI \\
\hline Energy & 9.01 & -121.17 to 139.19 \\
Total dietary fiber & -0.15 & -1.75 to 1.45 \\
Soluble dietary fiber & -0.15 & -0.64 to 0.33 \\
Insoluble dietary fiber & -0.05 & -1.27 to 1.17 \\
Calcium & -204.48 & -375.78 to $-33.19^{*}$ \\
PUFA 18:3 (linolenic acid) & -0.03 & -0.22 to 0.16 \\
\% calories from fat & -0.31 & -2.28 to 1.65 \\
\% calories from SFA & 0.09 & -0.89 to 1.08 \\
\% calories from MUFA & -0.13 & -0.91 to 0.66 \\
\% calories from PUFA & -0.26 & -1.21 to 0.69 \\
Omega-3-fatty Acids & 0.13 & -0.12 to 0.38 \\
\% calories from carbohydrate & -1.34 & -3.19 to 0.51 \\
\% calories from protein & 1.17 & 0.13 to $2.21^{*}$ \\
\hline
\end{tabular}

*Values are presented as regression coefficient $(95 \% \mathrm{CI})$ unless stated otherwise and control from baseline values. $P<0.001$.

(Table 3(a)). Lipids were done at baseline, 9 months, 18 months, or when the patient terminated the trial.

Total cholesterol reduction from baseline was $3.4 \mathrm{mg} / \mathrm{dL}$ $(P=0.129)$ at 9 months and $8.4 \mathrm{mg} / \mathrm{dL}(P \leq 0.001)$ at 18 months. $L D L$ was reduced significantly by $4.4 \mathrm{mg} / \mathrm{dL}$ at 9 months $(P=0.019)$ and $9.4 \mathrm{mg} / \mathrm{dL}$ at 18 months $(P \leq 0.001)$. HDL was significant: $4.0 \mathrm{mg} / \mathrm{dL}$ increase at 9 months $(P \leq 0.001)$ and $5.0 \mathrm{mg} / \mathrm{dL}$ increase at 18 months $(P<0.001)$. TC/HDL ratio decreased significantly over the time of the trial: a 0.26 reduction at 9 months $(P<$ $0.001)$ and a reduction of 0.43 at 18 months $(P<0.001)$. Triglycerides were log transformed for analysis and reporting of $P$ values. However, the coefficients and the differences reported are from the nonlog-transformed scale. Reductions in triglyceride concentrations were observed in all 3 groups (Table 3(a)). The overall decrease across the study period was $22.0 \mathrm{mg} / \mathrm{dL}$ at 9 months $(P<0.001)$ and $24.4 \mathrm{mg} / \mathrm{dL}$ at 18 months $(P<0.001)$. The TG reduction in the group treated with both oils was significantly greater $(P<0.031)$ than the borage oil or fish oil groups at 9 months, a pattern that persisted at 18 months (Table 3(b)). Atherogenic index of plasma $(A I P)$ was reduced in all 3 groups (Table $3(\mathrm{a}))$. The overall decrease across the study period was 0.22 at 9 months $(P<$ $0.001)$ and 0.26 at 18 months $(P<0.001)$. The reduction in the AIP was significantly greater $(P=0.011)$ at 9 months and 18 months in the group treated with both oils than that in the groups treated with either oil alone (Table 3(b)).

3.4. Sensitivity Analysis of Lipids. A sensitivity analysis was run to detect if missing data might have affected the study results. Missing data were imputed by substituting the baseline value. Since this would be the worst case scenario, in which all missing data return to baseline; analyses were repeated with the imputed data. The intragroup differences seen in triglyceride concentrations were not sustained with the imputed data. However, the intragroup differences seen with the AIP did persist. The significant change seen with all groups combined was also sustained with the imputed data, which indicates that missing data would not have a large impact on results from the all groups combined analyses.

3.5. Blood Pressure. Significant changes in blood pressure within and among groups were not observed. Systolic blood pressure increased $1.8 \mathrm{~mm}$ hg at 9 months and decreased $0.2 \mathrm{~mm}$ hg at 18 months. Diastolic blood pressure increased $2.3 \mathrm{mmhg}$ at 9 months and $1.9 \mathrm{mmhg}$ at 18 months (Table 4).

3.6. Erythrocyte Sedimentation Rate (ESR) [32] and C-Reactive Protein $(C R P)$. ESR is a common hematology test that is a nonspecific measure of inflammation. CRP is a protein found in the blood, and its levels increase in response to inflammation.

No significant differences in ESR or in CRP were seen among groups. However, when patients from all treatment groups were analyzed together, a modest but significant reduction in ESR was seen at 9 months, and ESR was still reduced from baseline at 18 months. A similar small but significant reduction in CRP was seen at 9 months, but not maintained at 18 months (Table 4).

\section{Discussion}

Part of the intrigue of research is the often unanticipated findings encountered. The current study was not designed to detect differences in lipids in patients with RA; hence, we lack a control group. Because marine and botanical oils given individually reduce joint inflammation in RA patients [14-18], and because the groups in this study showed improvement in the lipid profile, a trial of these oils with a placebo arm is warranted.

$\mathrm{RA}$ is a chronic systemic inflammatory disease. Mediators of inflammation and prothrombotic factors contribute to endothelial dysfunction and development of cardiovascular disease in RA patients [33]. There is little evidence that therapy for inflammation also leads to cardiovascular risk reduction in this group. Marine and botanical oils represent an excellent primary or secondary therapy for improvement of cardiovascular risk management in patients with rheumatoid arthritis.

Results of studies presented in this paper indicate that a GLA-enriched botanical oil (borage seed oil), an EPA/DHAenriched fish oil, or a combination of these oils are useful for correcting dyslipidemia in patients with RA. Since there were no differences observed between the groups, with the notable exception of triglycerides and the AIP (shown separately in Table 3(b)), all 3 treatment groups were analyzed as a single group. Although lipid profiles of most patients were acceptable at baseline, patients taking these oils exhibit significant additional reductions in total and LDL cholesterol, triglycerides, the TC/HDL ratio, and the atherogenic index, and experience a significant increase in HDL cholesterol. All of these improvements in the lipid profile were seen after 9 months of therapy and increased after 18 months of oils administration. Particularly noteworthy is the group treated with both oils, as they experienced a significantly greater reduction in serum triglyceride concentrations and in the AIP than the groups on either oil alone. Oils enriched in 
TABLE 3

(a) Serum Lipids and Atherogenic Index of Plasma

\begin{tabular}{|c|c|c|c|}
\hline & Baseline mean $(\mathrm{SD})(N=145)$ & $\begin{array}{l}\text { Change from baseline to } 9 \text { months } \\
\qquad(N=83)\end{array}$ & $\begin{array}{c}\text { Change from baseline to } 18 \\
\text { months }(N=69)\end{array}$ \\
\hline Total cholesterol & $195.77(37.48)$ & $\begin{array}{c}-3.45 \\
(-7.88 \text { to } 0.98)\end{array}$ & $\begin{array}{c}-8.43^{*} \\
(-12.99 \text { to }-3.86)\end{array}$ \\
\hline LDL & $114.63(32.20)$ & $\begin{array}{c}-4.39^{* *} \\
(-8.03 \text { to }-0.74)\end{array}$ & $\begin{array}{c}-9.43^{*} \\
(-13.75 \text { to }-5.11)\end{array}$ \\
\hline HDL & $54.14(16.21)$ & $\begin{array}{c}3.96^{*} \\
(2.44 \text { to } 5.49)\end{array}$ & $\begin{array}{c}5.02^{*} \\
(3.24 \text { to } 6.81)\end{array}$ \\
\hline $\mathrm{TC} / \mathrm{HDL}$ ratio $^{\dagger}$ & $3.83(1.03)$ & $\begin{array}{c}-0.26^{*} \\
(-0.41 \text { to }-0.12)\end{array}$ & $\begin{array}{c}-0.43^{*} \\
(-0.58 \text { to }-0.28)\end{array}$ \\
\hline Triglyceride $^{\dagger}$ & $138.05(79.65)$ & $\begin{array}{c}-21.96^{*} \\
(-30.52 \text { to }-13.40)\end{array}$ & $\begin{array}{c}-24.42^{*} \\
(-33.22 \text { to }-15.61)\end{array}$ \\
\hline Atherogenic index of plasma & $0.84(0.67)$ & $\begin{array}{c}-0.22^{*} \\
(-0.29 \text { to }-0.16)\end{array}$ & $\begin{array}{c}-0.26^{*} \\
(-0.33 \text { to }-0.19)\end{array}$ \\
\hline
\end{tabular}

Values are presented as regression coefficient $(95 \% \mathrm{CI})$ unless stated otherwise and control from baseline values. ${ }^{*} P<0.001 * * P \leq 0.05 \quad{ }^{\dagger} P$ value are from log-transformed data.

(b) Triglycerides and atherogenic index of plasma (AIP) by group

\begin{tabular}{|c|c|c|c|c|}
\hline & Combination group & Fish oil group & Borage oil group & $P$ value \\
\hline Triglyceride** & & & & 0.031 \\
\hline 9 months & $\begin{array}{c}-30.81 \\
(-46.58 \text { to }-15.03)\end{array}$ & $\begin{array}{c}-20.50 \\
(-35.16 \text { to }-5.85)\end{array}$ & $\begin{array}{c}-16.57 \\
(-30.86 \text { to }-2.27)\end{array}$ & \\
\hline 18 months & $\begin{array}{c}-38.24 \\
(-54.28 \text { to }-22.19)\end{array}$ & $\begin{array}{c}-15.27 \\
(-29.81 \text { to }-0.74)\end{array}$ & $\begin{array}{c}-22.10 \\
(-37.32 \text { to }-6.89)\end{array}$ & \\
\hline AIP & & & & 0.011 \\
\hline 9 months & $\begin{array}{c}-0.33 \\
(-0.45 \text { to }-0.20)\end{array}$ & $\begin{array}{c}-0.20 \\
(-0.32 \text { to }-0.08)\end{array}$ & $\begin{array}{c}-0.17 \\
(-0.33 \text { to } 0.002)\end{array}$ & \\
\hline 18 months & $\begin{array}{c}-0.45 \\
(-0.57 \text { to }-0.32)\end{array}$ & $\begin{array}{c}-0.16 \\
(-0.28 \text { to }-0.05)\end{array}$ & $\begin{array}{c}-0.21 \\
(-0.33 \text { to }-0.09)\end{array}$ & \\
\hline
\end{tabular}

\footnotetext{
${ }^{* *} P$ value is from $\log$ transformation. Changes shown are from the original scale for the group $\times$ time interaction and control for baseline values. Values are presented as regression coefficient $(95 \% \mathrm{CI})$.
}

TABle 4: Change from baseline for anthropometric and inflammatory markers.

\begin{tabular}{lcc}
\hline & 9 months $(N=88)$ & 18 months $(N=71)$ \\
\hline Weight $^{\dagger}$ & 0.52 & 0.35 \\
& $(-1.41$ to 2.46$)$ & $(-2.43$ to 3.14$)$ \\
$\begin{array}{l}\text { Systolic blood } \\
\text { pressure }\end{array}$ & 1.77 & -0.24 \\
$\begin{array}{l}\text { Diastolic blood } \\
\text { pressure }\end{array}$ & $(-0.66$ to 4.20$)$ & $(-3.37$ to 2.90$)$ \\
ESR & $(0.56$ to 4.09$)$ & $1.88^{* *}$ \\
& $-5.39^{*}$ & $(-0.003$ to 3.79$)$ \\
$\mathrm{CRP}^{\dagger}$ & $(-9.71$ to -1.07$)$ & $(-9.22$ to 0.38$)$ \\
& $-0.65^{*}$ & -0.09 \\
\hline
\end{tabular}

${ }^{*} P<0.001$.

$* * P \leq 0.05$.

${ }^{\dagger} P$ values are from log-transformed data.

$N=90$ at 9 months and $N=72$ at 18 months for blood pressure measurements.

$N=81$ at 9 months and $N=67$ at 18 months for ESR.

$N=66$ at 9 months and $N=58$ at 18 months for CRP.
GLA affect inflammation differently than oils enriched in EPA/DHA, and the anti-inflammatory and joint protective effects of the combination of these oils are synergistic in animal models [23]. Thus, it is possible that these different oils influence different aspects of TG synthesis or metabolism. Indeed, fish and botanical oils that provide EPA both reduce hepatic synthesis of TG in rats [34]. In humans the delta-5-desaturase that converts DGLA to arachidonic acid (AA) is sluggish, and we have not seen increases in circulating arachidonic acid after administration of GLA for 24 weeks [17]. Nonetheless, the possibility of increased circulating AA must be considered if treatment is to be long term. When fish oil is administered with borage oil to healthy individuals, bioconversion of GLA to AA is prevented [34], perhaps another reason for administering both GLA- and EPA-rich oils together.

All treatments were safe. Rates and types of adverse events were similar across all treatment groups, and as anticipated, were due entirely to mild to moderate gastrointestinal distress. The main reason for the large drop-out rate (in excess of $45 \%$ ) was the large size and the number 
of capsules ingested each day over the 18-month-study period. It is possible to deliver much larger amounts of the individual polyunsaturated fatty acids (GLA, EPA, and DHA) in far smaller capsules than are needed to accommodate the natural marine and botanical oils, a strategy which should substantially reduce the dropout rate.

Alterations in diet can influence serum lipid concentrations [35]. However, the patients in our study did not change their diets over the course of the trial, suggesting that the improvements in their lipid profiles, including the significant increase in HDL cholesterol, are due to administration of the study oils. Most pharmacological treatments of dyslipidemia address reduction of LDL cholesterol $[36,37]$. Since improvement in HDL cholesterol depends to a large extent on an exercise regimen $[13,38]$, many patients with RA are denied this manner of therapy. Thus, treatment with one or a combination of these oils could aid in the reduction of cardiovascular risk in RA patients whose disability impairs or prevents a prescribed exercise program.

Although LDL-C is the primary target of lipid-lowering therapy, other measures of the lipoprotein lipid profile, as reflected in the AIP and the TC/HDL-C ratios, are also associated with CVD risk. The AIP is a useful monitor of the lipid profile and its subsequent impact on the progression of cardiovascular risk [39]. In the study presented here, the AIP is significantly and beneficially altered at both 9 and 18 months compared to baseline. Patients in this study also exhibit a significant reduction in the TC/HDL ratio at 9 and 18 months, another indication of reduced CVD risk [40]. The safety of marine and botanical oils, and their remarkable impact observed in this study on the lipid profile of RA patients who are at increased risk for dyslipidemia and cardiovascular disease [1], suggest that these oils should have a prominent role in therapy of patients with RA.

Additionally, there is some evidence [41] that these oils can substitute for treatment of RA patients with nonsteroidal anti-inflammatory drugs (NSAIDs). The adverse gastrointestinal and renal events associated with NSAID therapy are well known [42]. In addition, macrophages treated with a cyclooxygenase inhibitor in vitro exhibit greater vulnerability to formation of foam cells, a key element in development of atheromatous plaques [43]. Neither borage oil nor fish oil is associated with serious gastrointestinal events (ulceration, bleeding, perforation). In addition, whereas NSAIDs increase the incidence of myocardial infarction and stroke [44], fish oil reduces the risk of cardiovascular events in patients at risk, including those with RA [45]. The efficacy of omega-3-fatty acids in reducing mortality after a myocardial infarction [46] is further reason to recommend their use in patients with RA. Although studies in humans of the influence of GLA on serum lipids are scant, GLA administration appears to prevent increases in TC and LDL-C [47].

\section{Conclusion}

Chronic inflammation, experienced by patients with RA, includes development of microthrombi in small vessels and production of inflammatory cytokines and is associated with accelerated atherosclerosis [48]. The capacity of both GLA- and EPA-rich oils to reduce platelet aggregation [49] and production of inflammatory cytokines [18] and the ability of EPA to form resolvins and protectins, compounds that facilitate resolution of inflammation [50], further suggest their potential long-term therapeutic value in patients with RA. The current study suggests their beneficial effect on cardiovascular risk factors in patients with RA. Additional studies of marine and botanical polyunsaturated fatty acids - in isolated form in order to reduce the number and the size of capsules administered-are warranted to further determine their influence on lipid dysfunction in patients with RA and other diseases characterized by chronic inflammation.

\section{Acknowledgments}

These studies were supported by the National Institutes of Health Grant RO1-AT000309 from the National Center for Complementary and Alternative Medicine. The authors are grateful for the statistical help of Robert Magner and the efforts of the principal investigators at the 13 sites and their patients, without whom this study would not have been possible.

\section{References}

[1] M. Boers, B. Dijkmans, S. Gabriel, H. Maradit-Kremers, J. O'Dell, and T. Pincus, "Making an impact on mortality in rheumatoid arthritis: targeting cardiovascular comorbidity," Arthritis and Rheumatism, vol. 50, no. 6, pp. 1734-1739, 2004.

[2] V. P. van Halm, M. J. L. Peters, A. E. Voskuyl et al., "Rheumatoid arthritis versus diabetes as a risk factor for cardiovascular disease: a cross-sectional study, the CARRÉ Investigation," Annals of the Rheumatic Diseases, vol. 68, no. 9, pp. 1395-1400, 2009.

[3] V. P. van Halm, M. M. Nielen, M. T. Nurmohamed et al., "Lipids and inflammation: Serial measurements of the lipid profile of blood donors who later developed rheumatoid arthritis," Annals of the Rheumatic Diseases, vol. 66, no. 2, pp. 184-188, 2007.

[4] W. H. Yoo, "Dyslipoproteinemia in patients with active rheumatoid arthritis: effects of disease activity, sex, and menopausal status on lipid profiles," Journal of Rheumatology, vol. 31, no. 9, pp. 1746-1753, 2004.

[5] G. Kerekes, Z. Szekanecz, H. Dér et al., "Endothelial dysfunction and atherosclerosis in rheumatoid arthritis: a multiparametric analysis using imaging techniques and laboratory markers of inflammation and autoimmunity," Journal of Rheumatology, vol. 35, no. 3, pp. 398-406, 2008.

[6] S. van Doornum, G. McColl, and I. P. Wicks, "Accelerated atherosclerosis: an extraarticular feature of rheumatoid arthritis?" Arthritis and Rheumatism, vol. 46, no. 4, pp. 862-873, 2002.

[7] V. P. van Halm, M. M. J. Nielen, M. T. Nurmohamed et al., "Lipids and inflammation: serial measurements of the lipid profile of blood donors who later developed rheumatoid arthritis," Annals of the Rheumatic Diseases, vol. 66, no. 2, pp. 184-188, 2007.

[8] S. clair, C. L. Wagner, A. A. Fasanmade et al., "The relationship of serum infliximab concentrations to clinical improvement in rheumatoid arthritis: results from ATTRACT, a multicenter, 
randomized, double-blind, placebo-controlled trial," Arthritis and Rheumatism, vol. 46, no. 6, pp. 1451-1459, 2002.

[9] D. Hürlimann, A. Forster, G. Noll et al., "Anti-tumor necrosis factor- $\alpha$ treatment improves endothelial function in patients with rheumatoid arthritis," Circulation, vol. 106, no. 17, pp. 2184-2187, 2002.

[10] E. N. Pollono, M. A. Lopez-Olivo, J. A. M. Lopez, and M. E. Suarez-Almazor, "A systematic review of the effect of TNF$\alpha$ antagonists on lipid profiles in patients with rheumatoid arthritis," Clinical Rheumatology, vol. 29, no. 9, pp. 947-955, 2010.

[11] M. J. L. Peters, M. Vis, V. P. van Halm et al., "Changes in lipid profile during infliximab and corticosteroid treatment in rheumatoid arthritis," Annals of the Rheumatic Diseases, vol. 66, no. 7, pp. 958-961, 2007.

[12] C. A. Wijbrandts, S. I. van Leuven, H. D. Boom et al., "Sustained changes in lipid profile and macrophage migration inhibitory factor levels after anti-tumour necrosis factor therapy in rheumatoid arthritis," Annals of the Rheumatic Diseases, vol. 68, no. 8, pp. 1316-1321, 2009.

[13] G. Steiner and M. B. Urowitz, "Lipid profiles in patients with rheumatoid arthritis: mechanisms and the impact of treatment," Seminars in Arthritis and Rheumatism, vol. 38, no. 5, pp. 372-381, 2009.

[14] G. Zuliani, M. Galvani, E. Leitersdorf, S. Volpato, M. Cavalieri, and R. Fellin, "The role of polyunsaturated fatty acids (PUFA) in the treatment of dyslipidemias," Current Pharmaceutical Design, vol. 15, no. 36, pp. 4087-4093, 2009.

[15] P. C. Weber, "Membrane phospholipid modification by dietary n-3 fatty acids: effects on eicosanoid formation and cell function," Progress in Clinical and Biological Research, vol. 282, pp. 263-274, 1988.

[16] J. D. Prickett, D. R. Robinson, and A. D. Steinberg, "Dietary enrichment with the polyunsaturated fatty acid eicosapentaenoic acid prevents proteinuria and prolongs survival in NZB x NZW F1 mice," Journal of Clinical Investigation, vol. 68 , no. 2, pp. 556-559, 1981.

[17] R. B. Zurier, R. G. Rossetti, E. W. Jacobson et al., "Gammalinolenic acid treatment of rheumatoid arthritis: a randomized, placebo-controlled trial," Arthritis and Rheumatism, vol. 39, no. 11, pp. 1808-1817, 1996.

[18] R. B. Zurier, "Prostaglandins, leukotrienes, and related compounds," in Kelley's Textbook of Rheumatology, G. S. Firestein, E. D. Harris, I. B. McIness, S. Ruddy, and J. S. Sergent, Eds., pp. 343-358, Saunders, Philadelphia, Pa, USA, 2009.

[19] D. Vassilopoulos, R. B. Zurier, R. G. Rossetti, and G. C. Tsokos, "Gammalinolenic acid and dihomogammalinolenic acid suppress the CD3- mediated signal transduction pathway in human T cells," Clinical Immunology and Immunopathology, vol. 83, no. 3, pp. 237-244, 1997.

[20] B. Bartok and G. S. Firestein, "Fibroblast-like synoviocytes: key effector cells in rheumatoid arthritis," Immunological Reviews, vol. 233, no. 1, pp. 233-255, 2010.

[21] V. A. Ziboh and R. S. Chapkin, "Biologic significance of polyunsaturated fatty acids in the skin," Archives of Dermatology, vol. 123, pp. 1686a-1690, 1987, Rheumatology. In press.

[22] P. C. Calder, "n-3 polyunsaturated fatty acids, inflammation, and inflammatory diseases," The American Journal of Clinical Nutrition, vol. 83, no. 6, Article ID 986797, pp. 1505S-1519S, 2006.

[23] G. A. Tate, B. F. Mandell, R. A. Karmali et al., "Suppression of monosodium urate crystal-induced acute inflammation by diets enriched with gamma-linolenic acid and eicosapen- taenoic acid," Arthritis and Rheumatism, vol. 31, no. 12, pp. 1543-1551, 1988.

[24] L. J. Leventhal, E. G. Boyce, and R. B. Zurier, "Treatment of rheumatoid arthritis with blackcurrant seed oil," British Journal of Rheumatology, vol. 33, no. 9, pp. 847-852, 1994.

[25] F. C. Arnett, S. M. Edworthy, D. A. Bloch et al., "The American Rheumatism Association 1987 revised criteria for the classification of rheumatoid arthritis," Arthritis and Rheumatism, vol. 31, no. 3, pp. 315-324, 1988.

[26] D. T. Felson, J. J. Anderson, M. Boers et al., "The American College of Rheumatology preliminary core set of disease activity measures for rheumatoid arthritis clinical trials," Arthritis and Rheumatism, vol. 36, no. 6, pp. 729-740, 1993.

[27] G. H. Beaton, J. Milner, and V. McGuire, "Source of variance in 24-hour dietary recall data: implications for nutrition study design and interpretation. Carbohydrate sources, vitamins, and minerals," American Journal of Clinical Nutrition, vol. 37, no. 6, pp. 986-995, 1983.

[28] Y. Ma, B. C. Olendzki, S. L. Pagoto et al., "Number of 24hour diet recalls needed to estimate energy intake," Annals of Epidemiology, vol. 19, no. 8, pp. 553-559, 2009.

[29] B. C. Olendzki, Y. Ma, J. R. Hébert et al., "Underreporting of energy intake and associated factors in a Latino population at risk of developing type 2 diabetes," Journal of the American Dietetic Association, vol. 108, no. 6, pp. 1003-1008, 2008.

[30] S. Mora, N. Rifai, J. E. Buring, and P. M. Ridker, "Comparison of LDL cholesterol concentrations by Friedewald calculation and direct measurement in relation to cardiovascular events in 27,331 women," Clinical Chemistry, vol. 55, no. 5, pp. 888894, 2009.

[31] A. Onat, G. Can, H. Kaya, and G. Hergenç, "”Atherogenic index of plasma" (log10 triglyceride/high-density lipoproteincholesterol) predicts high blood pressure, diabetes, and vascular events," Journal of Clinical Lipidology, vol. 4, no. 2, pp. 89-98, 2010.

[32] D. E. King, B. M. Egan, R. F. Woolson, A. G. Mainous III, Y. Al-Solaiman, and A. Jesri, "Effect of a high-fiber diet vs a fiber-supplemented diet on C-reactive protein level," Archives of Internal Medicine, vol. 167, no. 5, pp. 502-506, 2007.

[33] C. Jurcuţ, R. Jurcuţ, and C. Tanasescu, "Cardiovascular risk and rheumatoid arthritis: from mechanisms of atherosclerosis to therapeutic approach," Romanian Journal of Internal Medicine, vol. 42, no. 4, pp. 659-669, 2004.

[34] F. H. Chilton, L. L. Rudel, J. S. Parks, J. P. Arm, and M. C. Seeds, "Mechanisms by which botanical lipids affect inflammatory disorders," American Journal of Clinical Nutrition, vol. 87, no. 2, pp. 498S-503S, 2008.

[35] C. M. Berg, G. Lappas, E. Strandhagen et al., "Food patterns and cardiovascular disease risk factors: The Swedish INTERGENE research program," American Journal of Clinical Nutrition, vol. 88, no. 2, pp. 289-297, 2008.

[36] K. Miyauchi and H. Daida, "Clinical significance of intensive lipid-lowering therapy using statins in patients with coronary artery disease: LDL-cholesterol: the lower, the better; Is it true for Asians? (Pro)," Circulation Journal, vol. 74, no. 8, pp. 17181730, 2010.

[37] A. L. Catapano, "Perspectives on low-density lipoprotein cholesterol goal achievement," Current Medical Research and Opinion, vol. 25, no. 2, pp. 431-447, 2009.

[38] T. R. Thomas, S. O. Warner, K. C. Dellsperger et al., "Exercise and the metabolic syndrome with weight regain," Journal of Applied Physiology, vol. 109, no. 1, pp. 3-10, 2010. 
[39] M. Dobiášová, "Atherogenic index of plasma [log(triglycerides/HDL-cholesterol)]: theoretical and practical implications," Clinical Chemistry, vol. 50, no. 7, pp. 1113-1115, 2004.

[40] B. J. Arsenault, J. S. Rana, E. S. G. Stroes et al., "Beyond lowdensity lipoprotein cholesterol: respective contributions of non-high-density lipoprotein cholesterol levels, triglycerides, and the total cholesterol/high-density lipoprotein cholesterol ratio to coronary heart disease risk in apparently healthy men and women," Journal of the American College of Cardiology, vol. 55 , no. 1 , pp. 35-41, 2009.

[41] J. J. F. Belch, D. Ansell, R. Madhok, A. O’Dowd, and R. D. Sturrock, "Effects of altering dietary essential fatty acids on requirements for non-steroidal anti-inflammatory drugs in patients with rheumatoid arthritis: a double blind placebo controlled study," Annals of the Rheumatic Diseases, vol. 47, no. 2, pp. 96-104, 1988.

[42] N. J. Olsen, "Tailoring arthritis therapy in the wake of the NSAID crisis," New England Journal of Medicine, vol. 352, no. 25, pp. 2578-2580, 2005.

[43] E. S. L. Chan, H. Zhang, P. Fernandez et al., "Effect of cyclooxygenase inhibition on cholesterol efflux proteins and atheromatous foam cell transformation in THP-1 human macrophages: a possible mechanism for increased cardiovascular risk," Arthritis Research and Therapy, vol. 9, no. 1, article R4, 2007.

[44] M. Amer, V. R. Bead, J. Bathon, R. S. Blumenthal, and D. N. Edwards, "Use of nonsteroidal anti-inflammatory drugs in patients with cardiovascular disease: a cautionary tale," Cardiology in Review, vol. 18, no. 4, pp. 204-212, 2010.

[45] L. G. Cleland, G. E. Caughey, M. J. James, and S. M. Proudmam, "Reduction of cardiovascular risk factors with longterm fish oil treatment in early rheumatoid arthritis," Journal of Rheumatology, vol. 33, no. 10, pp. 1973-1979, 2006.

[46] P. E. Marik and J. Varon, "Omega-3 dietary supplements and the risk of cardiovascular events: a systematic review," Clinical Cardiology, vol. 32, no. 7, pp. 365-372, 2009.

[47] R. L. Tahvonen, U. S. Schwab, K. M. Linderborg, H. M. Mykkänen, and H. P. Kallio, "Black currant seed oil and fish oil supplements differ in their effects on fatty acid profiles of plasma lipids, and concentrations of serum total and lipoprotein lipids, plasma glucose and insulin," Journal of Nutritional Biochemistry, vol. 16, no. 6, pp. 353-359, 2005.

[48] A. Sodergren, K. Karp, K. Boman et al., "Atherosclerosis in early rheumatoid arthritis: very early endothelial activation and rapid progression of intima media thickness," Arthritis Research \& Therapy, vol. 12, no. 4, R158, 2010.

[49] P. C. Calder and R. B. Zurier, "Polyunsaturated fatty acids and rheumatoid arthritis," Current Opinion in Clinical Nutrition and Metabolic Care, vol. 4, no. 2, pp. 115-121, 2001.

[50] C. N. Serhan, N. Chiang, and T. E. van Dyke, "Resolving inflammation: dual anti-inflammatory and pro-resolution lipid mediators," Nature Reviews Immunology, vol. 8, no. 5, pp. 349-361, 2008. 


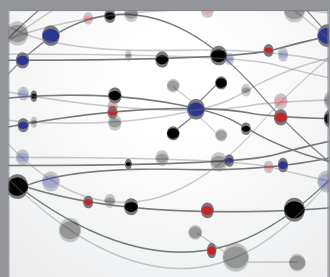

The Scientific World Journal
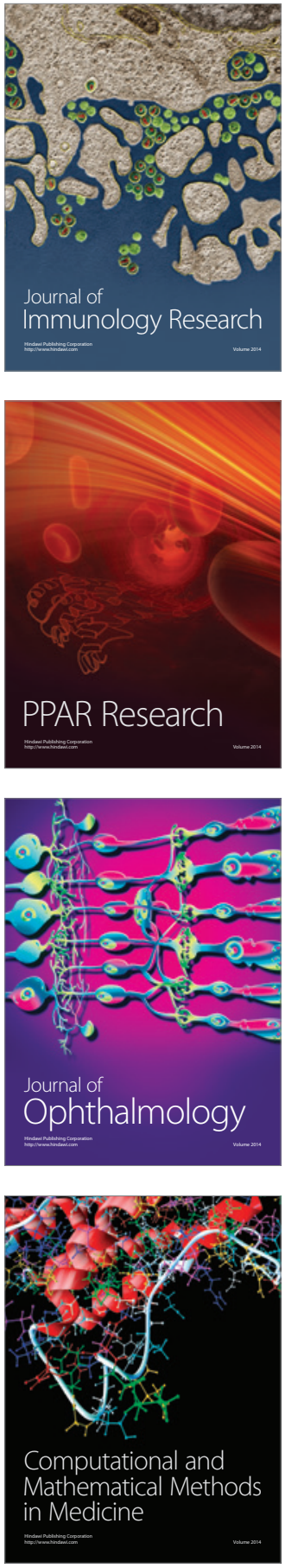

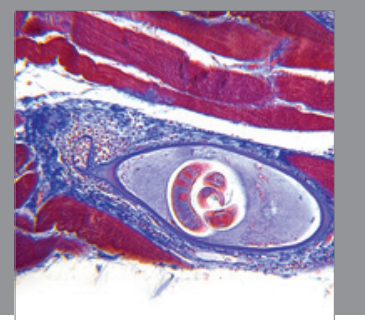

Gastroenterology

Research and Practice
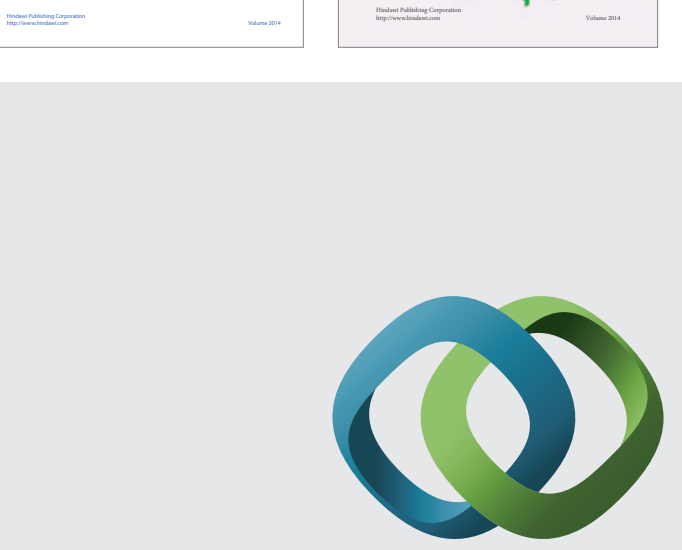

\section{Hindawi}

Submit your manuscripts at

http://www.hindawi.com
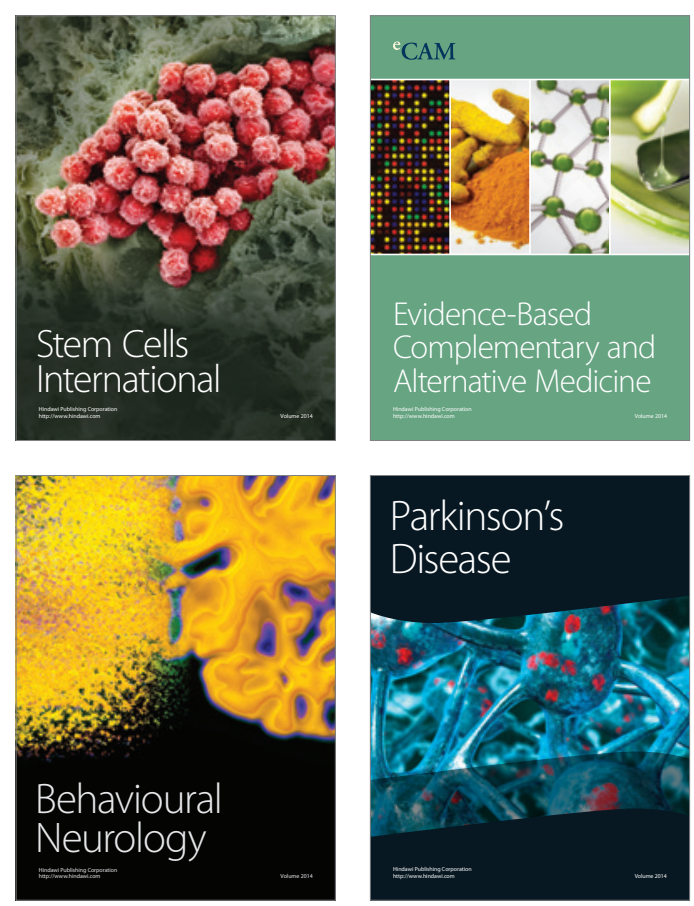

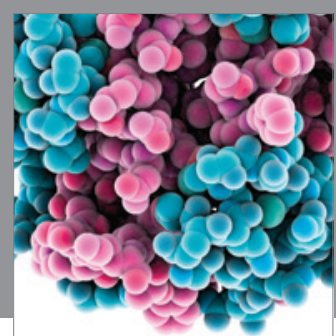

Journal of
Diabetes Research

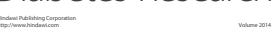

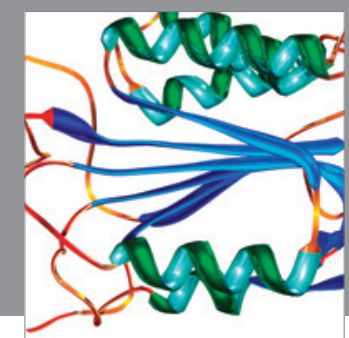

Disease Markers
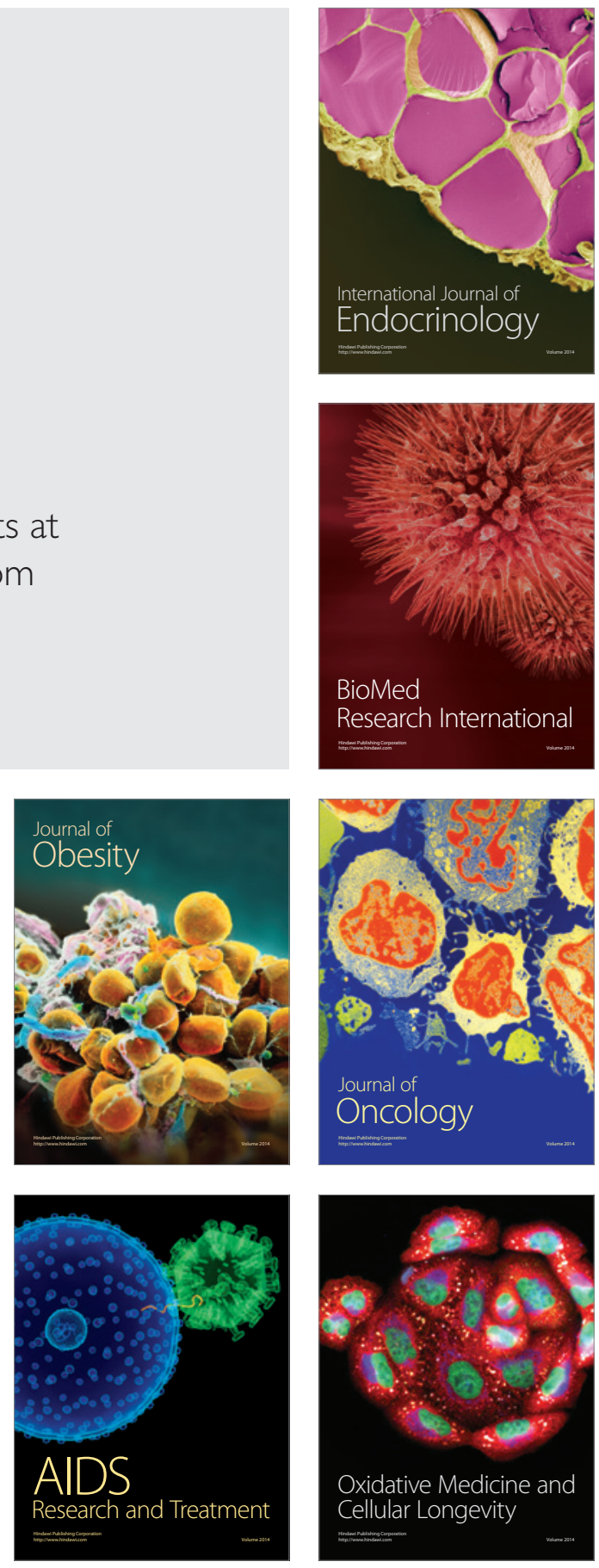